Article

\title{
Inverted-Type InAlAs/InAs High-Electron-Mobility Transistor with Liquid Phase Oxidized InAlAs as Gate Insulator
}

\author{
Yuan-Ming Chen ${ }^{1}$, Hsien-Cheng Lin ${ }^{2}$, Kuan-Wei Lee ${ }^{3, *(D)}$ and Yeong-Her Wang ${ }^{1,2, *(D)}$ \\ 1 Institute of Electro-Optical Science and Engineering, National Cheng-Kung University, Tainan 701, Taiwan; \\ o6685@hotmail.com \\ 2 Institute of Microelectronics, Department of Electrical Engineering, National Cheng-Kung University, \\ Tainan 701, Taiwan; pp3129@yahoo.com.tw \\ 3 Department of Electronic Engineering, I-Shou University, Kaohsiung 840, Taiwan \\ * Correspondence: kwlee@isu.edu.tw (K.-W.L.); yhw@ee.ncku.edu.tw (Y.-H.W.)
}

Citation: Chen, Y.-M.; Lin, H.-C.; Lee, K.-W.; Wang, Y.-H. Inverted-Type InAlAs/InAs High-Electron-Mobility Transistor with Liquid Phase Oxidized InAlAs as Gate Insulator. Materials 2021, 14, 970. https:// doi.org/10.3390/ma14040970

Academic Editor: Albena Paskaleva

Received: 6 January 2021

Accepted: 14 February 2021

Published: 18 February 2021

Publisher's Note: MDPI stays neutral with regard to jurisdictional claims in published maps and institutional affiliations.

Copyright: (c) 2021 by the authors. Licensee MDPI, Basel, Switzerland. This article is an open access article distributed under the terms and conditions of the Creative Commons Attribution (CC BY) license (https:// creativecommons.org/licenses/by/ $4.0 /)$.

\begin{abstract}
An inverted-type InAlAs/InAs metal-oxide-semiconductor high-electron-mobility transistor (MOS-HEMT) with liquid phase oxidized (LPO) InAlAs as the gate insulator is demonstrated. A thin InAs layer is inserted in the sub-channel layers of InGaAs to enhance the device performance. The proposed inverted-type InAlAs/InAs MOS-HEMT exhibits an improved maximum drain current density, higher transconductance, lower leakage current density, suppressed noise figures, and enhanced associated gain compared to the conventional Schottky-gate HEMT. Employing LPO to generate MOS structure improves the surface states and enhances the energy barrier. These results reveal that the proposed inverted-type InAlAs/InAs MOS-HEMT can provide an alternative option for device applications.
\end{abstract}

Keywords: inverted-type; InAs; metal-oxide-semiconductor (MOS); high-electron-mobility transistor (HEMT)

\section{Introduction}

The conventional Si-based field effect transistors are reaching the scaling limit in logic devices [1]. High-indium-content compound semiconductors with high electron mobility of more than $8500 \mathrm{~cm}^{2} / \mathrm{Vs}$, as well as gate insulators, are being considered as alternative channel materials for the future in the complementary metal-oxide-semiconductor fieldeffect transistor (MOSFET) industry. To achieve low noise figures in future radio frequency (RF) applications, InP-based high-electron-mobility transistors (HEMTs) with InGaAs channels have demonstrated very high levels of performance and have been widely used in circuits operating in the microwave range [2,3]. Many efforts have been made recently to obtain higher performance by designing novel channel structures. For instance, Ng et al. [4] reported that a high indium ratio (65\%) InGaAs channel InAlAs/InGaAs HEMT resulted in $13 \%$ improvement in terms of mobility $\left(11,200\right.$ to $\left.9900 \mathrm{~cm}^{2} / \mathrm{Vs}\right)$ compared to $53 \%$ indium at room temperature. Matsumura et al. [5] reported that inserting an InAs monolayer within the channel of an AlGaAs/InGaAs HEMT resulted in a 15\% improvement in mobility compared to a channel without an InAs monolayer at room temperature. Eugster et al. [6] reported that using a thin InAs channel in InAlAs/InAs modulation-doped field-effect transistor (MODFET) resulted in low output conductance and a high breakdown voltage. It is expected that such devices will benefit from the high mobility of InAs, $40,000 \mathrm{~cm}^{2} / \mathrm{Vs}$, and will thus exhibit high-speed operation and low power consumption. Some studies have also fabricated InAs or InGaAs HEMTs on Si substrates and have shown excellent results [7,8]. In addition, the inverted-type HEMT design [9-11] is also an interesting concept (i.e., the carrier supply layer or donor layer is designed below the channel layer). The advantage of an inverted-type HEMT is that the threshold voltage can be easily controlled through gate recess without a reduction in the drain current due to the etching 
of the upper donor layer. Akazaki et al. [10] reported that the inverted-type HEMT with an InGaAs/InAs/InGaAs channel structure exhibits only a small kink effect and has higher breakdown voltage.

An $\operatorname{In}_{0.52} \mathrm{Al}_{0.48}$ As Schottky layer with high aluminum content may suffer from the leakage current issue, which causes a reduction in the breakdown voltage. Additionally, an HEMT with high indium content suffers from impact ionization due to the narrow bandgap channel, which induces a higher gate leakage current. One commonly used method to address this issue is to insert a dielectric layer between the metal gate and the $\mathrm{In}_{0.52} \mathrm{Al}_{0.48} \mathrm{As}$ layer to supply a high energy barrier. Several laboratories have announced successful results related to the preparation of oxide film on semiconductors, such as thermal oxidation [12], chemical anodization [13], photochemical oxidation [14], molecular beam epitaxy (MBE) [15], and atomic layer deposition (ALD) [16]. In particular, oxidized InAlAs developed using the UV/ozone process [17] and wet oxidation [18] has been reported. Compared with the experimental apparatus mentioned above, the liquid phase oxidation (LPO) [19] operated at near room temperature (e.g., $50{ }^{\circ} \mathrm{C}$ ) only requires a $\mathrm{pH}$ meter and a constant temperature groove to grow an oxide film on semiconductors, whereas a technique that does not require any anodic equipment or assisting energy source is used to grow smooth native oxide films. The technique was successfully demonstrated on InAlAs [20-22] and showed promising experimental results for the metamorphic HEMTs on a GaAs substrate with an InGaAs channel. In this work, InAlAs film was oxidized using LPO as the gate insulator to fabricate an inverted-type InAlAs/InAs metal-oxidesemiconductor high-electron-mobility transistor (MOS-HEMT), where a thin InAs layer was inserted within the InGaAs sub-channel layers to improve the device performance.

\section{Experimental}

For preparing the LPO growth solution, gallium-ion-containing nitric acid solution was obtained through the sufficient dissolution of high purity $(6 \mathrm{~N})$ gallium metal in heat $\left(60^{\circ} \mathrm{C}\right)$ and concentrated nitric acid $(70 \%)$ for more than $8 \mathrm{~h}$, and was then diluted with deionized (DI) water [19]. Next, the optimum $\mathrm{pH}$ value was adjusted by adding an ammonia solution into the nitric acid solution. Finally, a clear solution with a pore size less than $0.1 \mu \mathrm{m}$ was obtained using filtration. The growth solution was composed of ammonium nitrate salt $\left(\mathrm{NH}_{4} \mathrm{NO}_{3}\right)$ and a little nitric acid. When the growth solution was heated using a temperature-controlled heater (e.g., $\left.50^{\circ} \mathrm{C}\right)$, the hydrolysis reaction of the ammonium nitrate solution generated ammonia gas and nitric acid. This can be described as Formula (1). Nitric acid oxidizes GaAs-based materials because it is a strong oxidizing reagent. In general, nitric acid is easier to decompose due to absorption heat and can be described as Formula (2).

$$
\begin{gathered}
\mathrm{NH}_{4} \mathrm{NO}_{3(\mathrm{aq})} \rightarrow \mathrm{NH}_{3(\mathrm{~g})}+\mathrm{HNO}_{3(\mathrm{aq})} \\
4 \mathrm{HNO}_{3(\mathrm{aq})} \rightarrow 4 \mathrm{NO}_{(\mathrm{g})}+3 \mathrm{O}_{2(\mathrm{~g})}+2 \mathrm{H}_{2} \mathrm{O}_{(\mathrm{aq})} \\
4 \mathrm{In}+3 \mathrm{O}_{2} \rightarrow 2 \mathrm{In}_{2} \mathrm{O}_{3} \\
4 \mathrm{Al}+3 \mathrm{O}_{2} \rightarrow 2 \mathrm{Al}_{2} \mathrm{O}_{3} \\
4 \mathrm{As}+3 \mathrm{O}_{2} \rightarrow 2 \mathrm{As}_{2} \mathrm{O}_{3}
\end{gathered}
$$

Figure 1a demonstrates the X-ray photoelectron spectroscopy (XPS, PHI 5000 VersaProbe, Physical Electronics, Chanhassen, MN, USA) depth profiles of the as-grown sample on InAlAs. The as-grown LPO-oxide film (referring to Formulas (3) to (5)) was composed of $\mathrm{Al}_{2} \mathrm{O}_{3}, \mathrm{As}_{2} \mathrm{O}_{3}$, and $\operatorname{In}_{2} \mathrm{O}_{3}$. However, there were almost no $\mathrm{Al}$ oxides on the surface after $1 \mathrm{~h}$ oxidation, which was similar to the results in reference [20]. Figure $1 \mathrm{~b}$ shows the cross-sectional transmission electron microscope (TEM, JEOL JEM-2010, Akishima, Japan) image of the oxidized InAlAs. The oxide film on the InAlAs layer was found to be approximately $6 \mathrm{~nm}$ thick. 


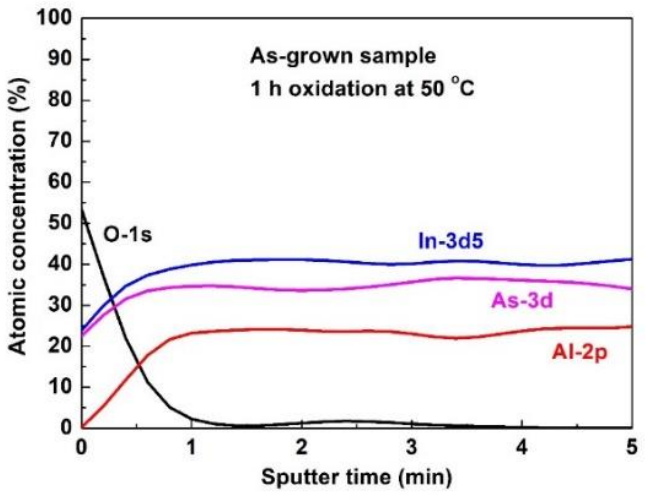

(a)

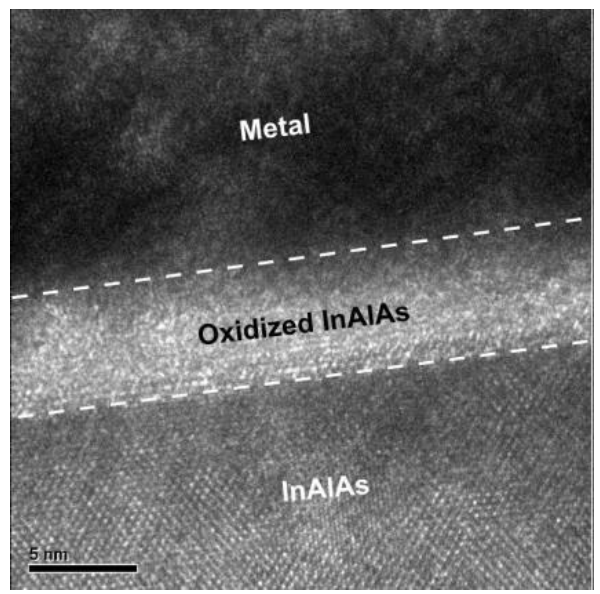

(b)

Figure 1. (a) XPS depth profiles of the as-grown sample on InAlAs. (b) Cross-sectional TEM image of oxidized InAlAs.

The device structure was grown using the MBE system on a 3 inch semi-insulating InP substrate. It was composed of a $300 \mathrm{~nm}$ undoped InAlAs buffer layer, a $6 \mathrm{~nm}$ InAlAs donor layer with a silicon doping density of $4 \times 10^{18} \mathrm{~cm}^{-3}$, a $6 \mathrm{~nm}$ undoped InAlAs spacer layer, a $3 \mathrm{~nm}$ undoped $\mathrm{In}_{0.53} \mathrm{Ga}_{0.47}$ As sub-channel layer, a $2 \mathrm{~nm}$ undoped InAs channel layer, a $13 \mathrm{~nm}$ undoped $\mathrm{In}_{0.53} \mathrm{Ga}_{0.47}$ As sub-channel layer, a $20 \mathrm{~nm}$ undoped InAlAs Schottky layer, and a $2.5 \mathrm{~nm}$ undoped InAs capping layer. Room temperature Hall measurements showed electron mobility of $14,262 \mathrm{~cm}^{2} /$ Vs and a sheet carrier concentration of $2.07 \times 10^{12} \mathrm{~cm}^{-2}$. Figure 2 shows schematic structures of inverted-type InAlAs/InAs HEMTs as the reference sample and the proposed MOS-HEMTs with oxidized InAlAs as the gate insulator. The device mesa isolation was conducted through a wet etching method using an $\mathrm{H}_{3} \mathrm{PO}_{4}$-based solution. Mesa etching should reach the buffer layer. After forming the ohmic alloy with $\mathrm{Au} / \mathrm{Ge} / \mathrm{Ni}$ by evaporation and annealing at $420{ }^{\circ} \mathrm{C}$ for $30 \mathrm{~s}$ in an $\mathrm{N}_{2}$ atmosphere, gate recess was performed using a citric-acid-based etchant. For MOS-HEMT fabrication, LPO was used to generate the gate insulator by immersing the post-etching samples into the growth solution. The thickness of gate oxide was approximately $11 \mathrm{~nm}$. Finally, the gate metal was deposited with Au for the reference HEMT and the MOS-HEMT. Figure 3a,b shows the 2D and 3D atomic force microscopy (AFM) images of the InAlAs surface after the gate recess process, respectively. The measured area was $5 \times 5 \mu \mathrm{m}$, and the root mean square (RMS) value of the surface was $1.63 \mathrm{~nm}$. Figure 3c,d shows the 2D and 3D AFM images of the oxidized InAlAs surface after the LPO process, respectively. The related RMS value of the surface was $1.53 \mathrm{~nm}$. The surface roughness of the interface underneath the metal gate influences the DC and RF performance of the HEMTs. Improved surface roughness of oxidized InAlAs using LPO was beneficial to the device performance. 


\begin{tabular}{|c|}
\hline i-InAs capping layer $2.5 \mathrm{~nm}$ \\
\hline i-In0.52Al0.48As Schottky layer $20 \mathrm{~nm}$ \\
\hline i-In0.53Ga0.47As sub-channel layer $13 \mathrm{~nm}$ \\
\hline i-InAs channel layer $2 \mathrm{~nm}$ \\
\hline i-In0.53Ga0.47As sub-channel layer $3 \mathrm{~nm}$ \\
\hline i-In0.52Al0.48As spacer layer $6 \mathrm{~nm}$ \\
\hline $\mathrm{n}^{+}$In0.52Al0.48As donor layer $6 \mathrm{~nm}$ \\
\hline i-In0.52Al0.48As buffer layer $300 \mathrm{~nm}$ \\
\hline 3" S.I. InP substrate \\
\hline
\end{tabular}

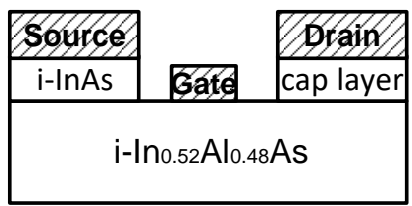

\section{Reference HEMT}

\begin{tabular}{|c|c|c|}
\hline \multirow{2}{*}{$\begin{array}{l}\text { 8ource } \\
\mathrm{i}-\ln A \mathrm{~s}\end{array}$} & \multirow{2}{*}{ Gata } & orain \\
\hline & & cap layer \\
\hline & oxide & \\
\hline & $\ln 0.52 \mathrm{~A}$ & ${ }_{8}$ As \\
\hline
\end{tabular}

MOS-HEMT

Figure 2. Schematic structures of the Schottky-gate InAlAs/InAs high-electron-mobility transistor (HEMT) and the proposed InAlAs/InAs metal-oxide-semiconductor (MOS)-HEMT.

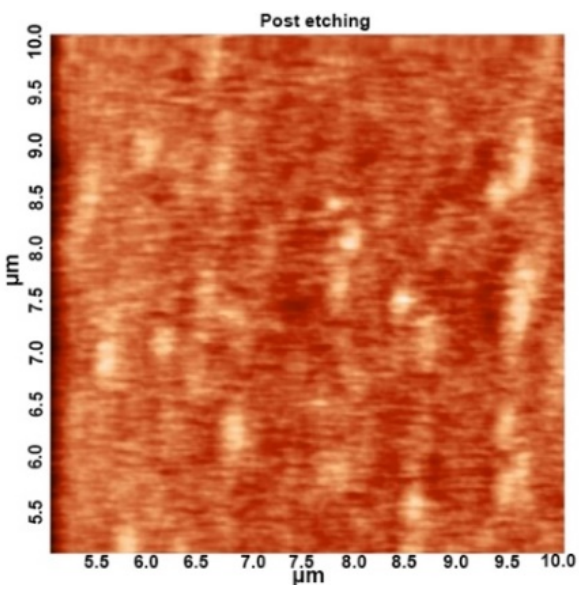

(a)

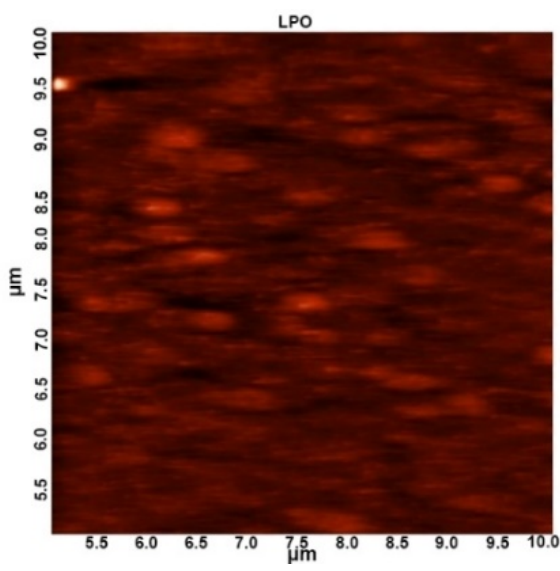

(c)

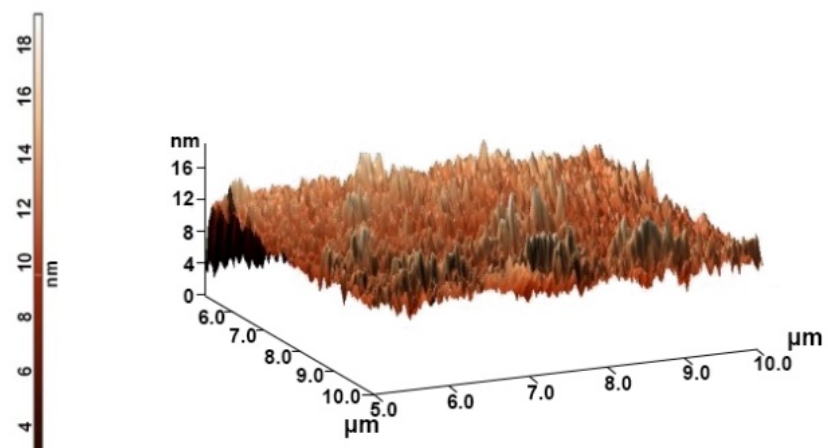

(b)

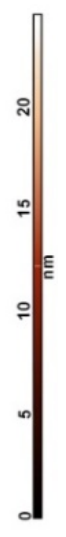

(d)

Figure 3. (a) 2D and (b) 3D atomic force microscopy (AFM) images of post-etching InAlAs layer. (c) 2D and (d) 3D AFM images of oxidized InAlAs surface. 


\section{Results and Discussion}

Figure 4 shows the measured drain current density $\left(\mathrm{I}_{\mathrm{DS}}\right)$ versus the drain-to-source voltage $\left(\mathrm{V}_{\mathrm{DS}}\right)$ characteristics of the conventional HEMT and MOS-HEMT with a gate length and width of $1 \mu \mathrm{m}$ and $100 \mu \mathrm{m}$, respectively. The gate-to-source voltage $\left(\mathrm{V}_{\mathrm{GS}}\right)$ ranged from -1.4 to $1.4 \mathrm{~V}$ in $0.4 \mathrm{~V}$ steps. The maximum $\mathrm{I}_{\mathrm{DS}}$ of the reference HEMT was $441 \mathrm{~mA} / \mathrm{mm}$ at $\mathrm{V}_{\mathrm{DS}}=1.5 \mathrm{~V}$. The maximum $\mathrm{I}_{\mathrm{DS}}$ of the MOS-HEMT was $509 \mathrm{~mA} / \mathrm{mm}$ at $\mathrm{V}_{\mathrm{DS}}=1.5 \mathrm{~V}$, which is higher than that of the reference HEMT. It was difficult to obtain the completed pinch-off characteristics for both devices. The reason why such devices do not turn off completely has been attributed to the carrier supply layer being far away from the metal gate or donor-type traps located in the lower portion of the energy bandgap at the InAlAs/oxide interface [23], which means the charged state will be positive after losing electrons when negative voltage is applied to the gate.

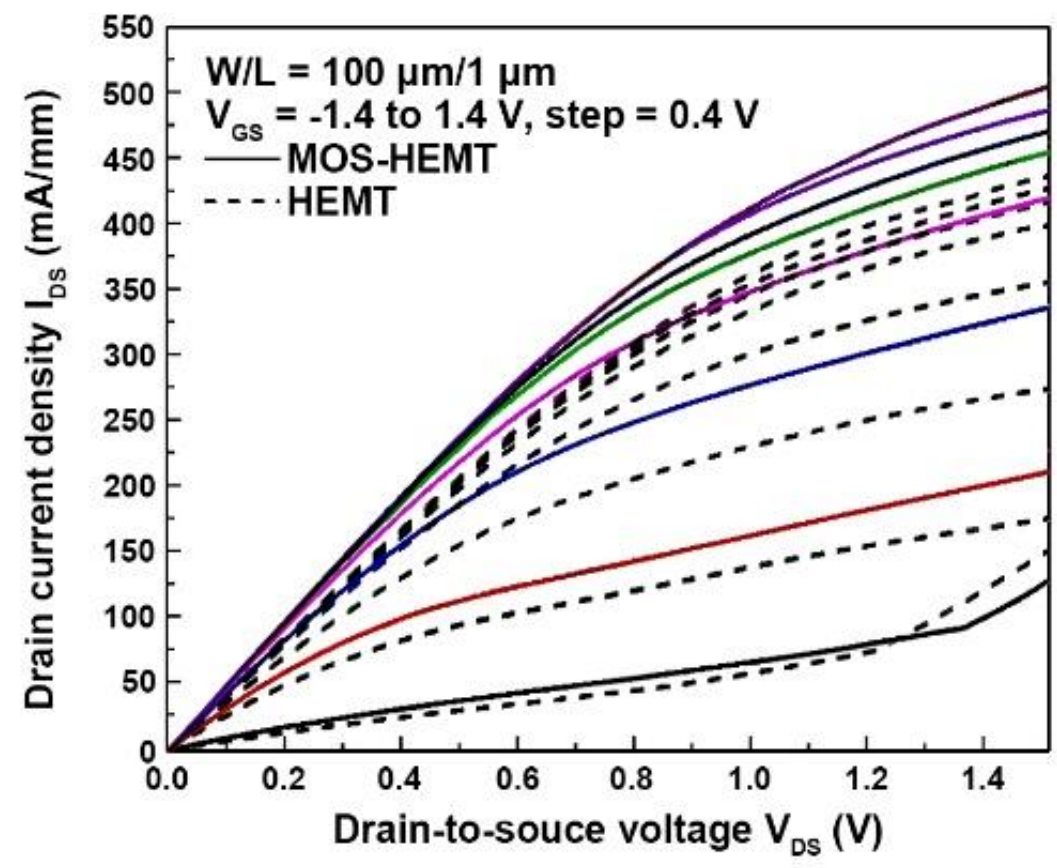

Figure 4. The comparison of measured drain current density ( $\left.\mathrm{I}_{\mathrm{DS}}\right)$ versus the drain-to-source voltage $\left(\mathrm{I}_{\mathrm{DS}}-\mathrm{V}_{\mathrm{DS}}\right.$ ) characteristics for reference HEMT and MOS-HEMT. The oxide thickness is $11 \mathrm{~nm}$ for MOS-HEMT.

The $\mathrm{I}_{\mathrm{DS}}$ and related transconductance $\left(\mathrm{g}_{\mathrm{m}}\right)$ versus $\mathrm{V}_{\mathrm{GS}}$ at $\mathrm{V}_{\mathrm{DS}}=1.5 \mathrm{~V}$ for both devices are shown in Figure 5. The maximum extrinsic $g_{m}$ was $243 \mathrm{mS} / \mathrm{mm}$ and the threshold voltage was $-1.9 \mathrm{~V}$ for the reference HEMT. The maximum extrinsic $\mathrm{g}_{\mathrm{m}}$ was $327 \mathrm{mS} / \mathrm{mm}$ and the threshold voltage was $-1.7 \mathrm{~V}$ for the proposed MOS-HEMT. The band bending in the InAlAs Schottky layer is affected at the higher gate bias, and the conduction band has a chance to be lower than the Fermi level, leading to a small $\mathrm{g}_{\mathrm{m}}$ at higher $\mathrm{V}_{\mathrm{GS}}$. The enhanced $\mathrm{I}_{\mathrm{DS}}$ and $g_{m}$ characteristics were attributed to the improvement in the oxide/InAlAs interface. 


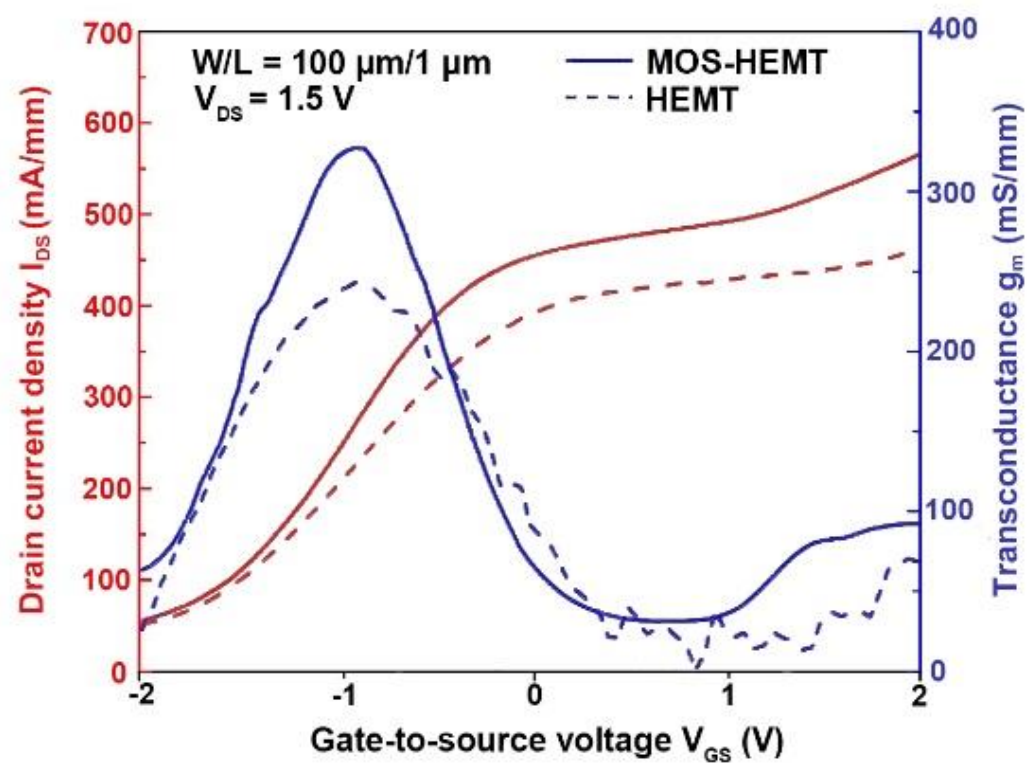

Figure 5. The comparison of transconductance $\left(\mathrm{g}_{\mathrm{m}}\right)$ and $\mathrm{I}_{\mathrm{DS}}$ versus gate-to-source voltage $\left(\mathrm{V}_{\mathrm{GS}}\right)$ at a fixed $\mathrm{V}_{\mathrm{DS}}$ of $1.5 \mathrm{~V}$ for the reference HEMT and MOS-HEMT.

Figure $6 \mathrm{a}, \mathrm{b}$ demonstrates the measured gate current density as a function of $\mathrm{V}_{\mathrm{GS}}$ for the reference HEMT and the proposed MOS-HEMT, respectively. The $\mathrm{V}_{\mathrm{DS}}$ ranged from 0.5 to $1.5 \mathrm{~V}$ in $0.5 \mathrm{~V}$ steps. The gate current density for the MOS-HEMT was significantly suppressed by at least two orders of magnitude compared to that of the reference HEMT. Please note that this is expressed on a logarithm scale, so the change in the current density is obvious. The enhanced impact ionization was due to the higher electric field existing around the gate-to-drain region where the hot carrier phenomena occurred in the narrow composite channel in the case of the reference HEMT. In the MOS-HEMT, the electric field was weaker than that of the Schottky-gate HEMT owing to the oxidized InAlAs between the metal gate and the InAlAs Schottky layer.

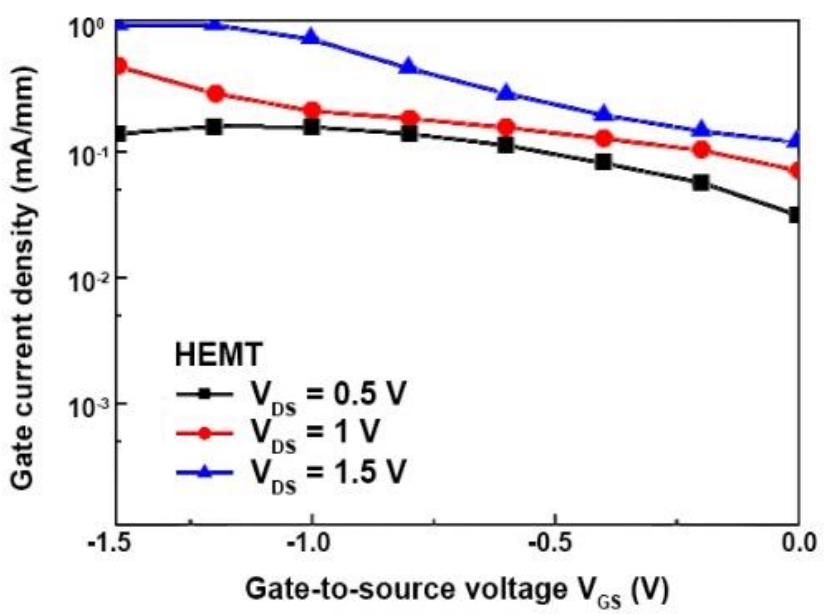

(a)

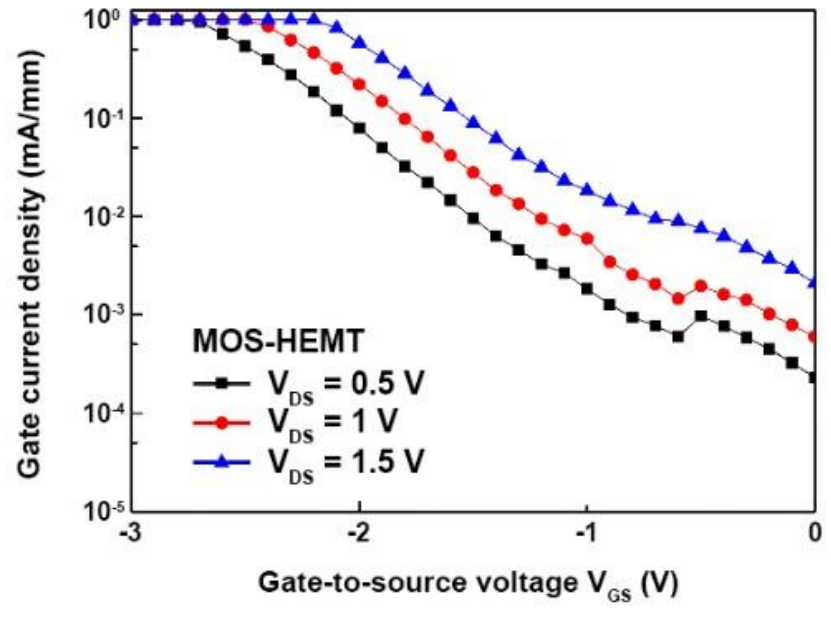

(b)

Figure 6. The gate current density versus $V_{G S}$ at distinct $V_{D S}$ for (a) reference HEMT and (b) MOS-HEMT. 
Figure 7a,b shows the gate leakage current of two-terminal diode characteristics for forward and reverse gate-to-drain voltage $\left(\mathrm{V}_{\mathrm{GD}}\right)$ for both devices, respectively. In this measurement, the source terminal was floating and the drain terminal was grounded. The turn-on voltages of the Schottky-gate HEMT and the MOS-HEMT were 1.54 and $3.98 \mathrm{~V}$, respectively. The corresponding reverse gate-to-drain breakdown voltages of the reference HEMT and the MOS-HEMT were -2.5 and $-4.6 \mathrm{~V}$, respectively. In general, a higher turn-on voltage or reverse gate-to-drain breakdown voltage accompanies a smaller gate leakage current and higher gate voltage swing. In addition, a larger turn-on voltage allows a higher $\mathrm{I}_{\mathrm{DS}}$ in the composite channel, which improves the device power and is consistent with the results shown in Figure 5.

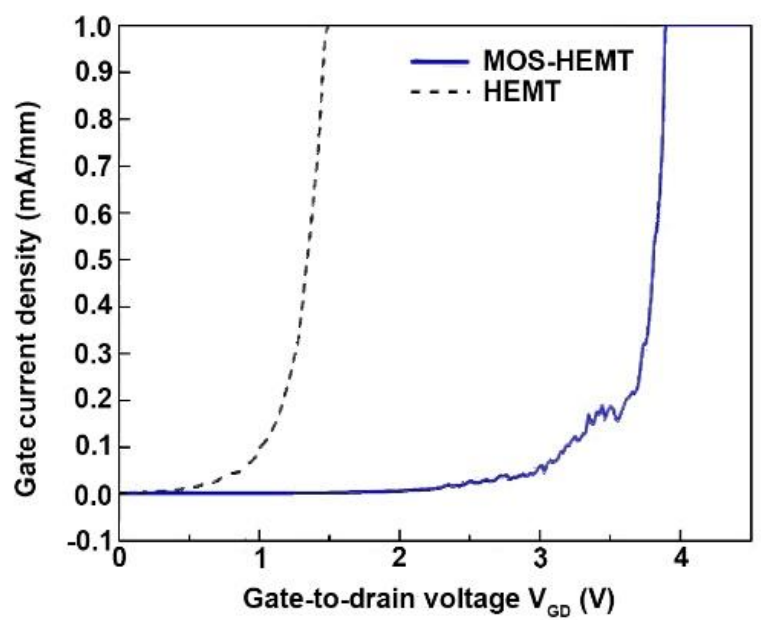

(a)

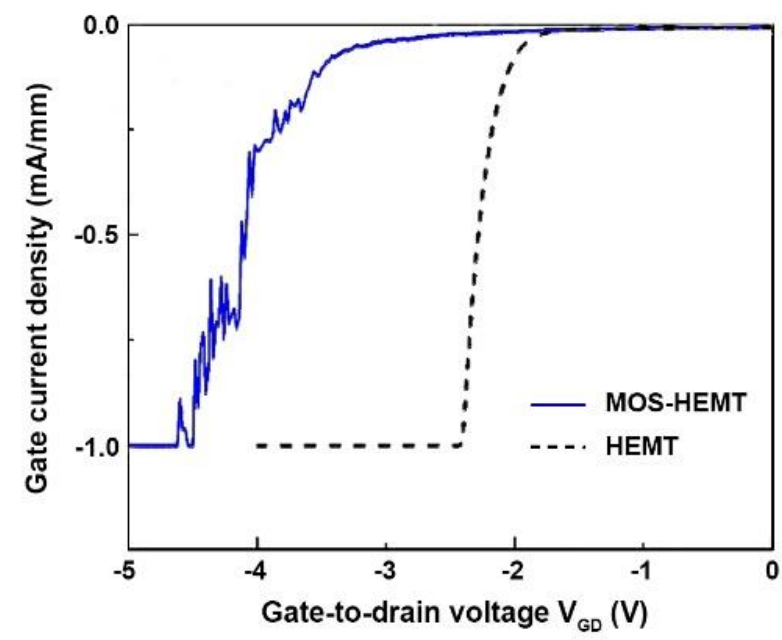

(b)

Figure 7. The gate leakage current of two-terminal diode characteristics for (a) forward biases and (b) reverse biases for both devices.

With the increasing demands of wireless communication, applications with low noise figures and high associated gains are required [24,25]. Circuit noise is characterized by the noise figure, which is defined as the signal-to-noise ratio at the amplifier output divided by the signal-to-noise ratio at the input. The minimum noise figure $\left(\mathrm{NF}_{\min }\right)$ can be obtained as Formula (6):

$$
N F_{\text {min }} \cong 1+\left(\frac{f}{f_{T}}\right) K_{f} \sqrt{g_{m}\left(R_{s}+R_{g}\right)}
$$

where $f$ is the operating frequency; $f_{\mathrm{T}}$ is cutoff frequency; $K_{f}$ is the Fukui factor; $R s$ is the source series resistance; $R g$ is the gate series resistance [26]. The formula describes the behavior of GaAs metal-semiconductor field-effect transistor (MESFET) and can be used for a qualitative discussion of high-frequency noise of HEMT. Figure 8 presents a comparison of the noise and gain performances measured at $0.6 \mathrm{GHz}$ intervals between 1.2 and $7.2 \mathrm{GHz}$ for both devices. The measured noise figures of the HEMT (MOS-HEMT) increased from $9.44 \mathrm{~dB}(5.88 \mathrm{~dB})$ at $1.2 \mathrm{GHz}$ to $10.75 \mathrm{~dB}(8.75 \mathrm{~dB})$ at $7.2 \mathrm{GHz}$. The associated gains of the HEMT (MOS-HEMT) decreased from $9.74 \mathrm{~dB}(15.67 \mathrm{~dB})$ at $1.2 \mathrm{GHz}$ to $0 \mathrm{~dB}(1.56 \mathrm{~dB})$ at 7.2 GHz. The higher noise figure may have been due to the probe pad resistances during measurement. 


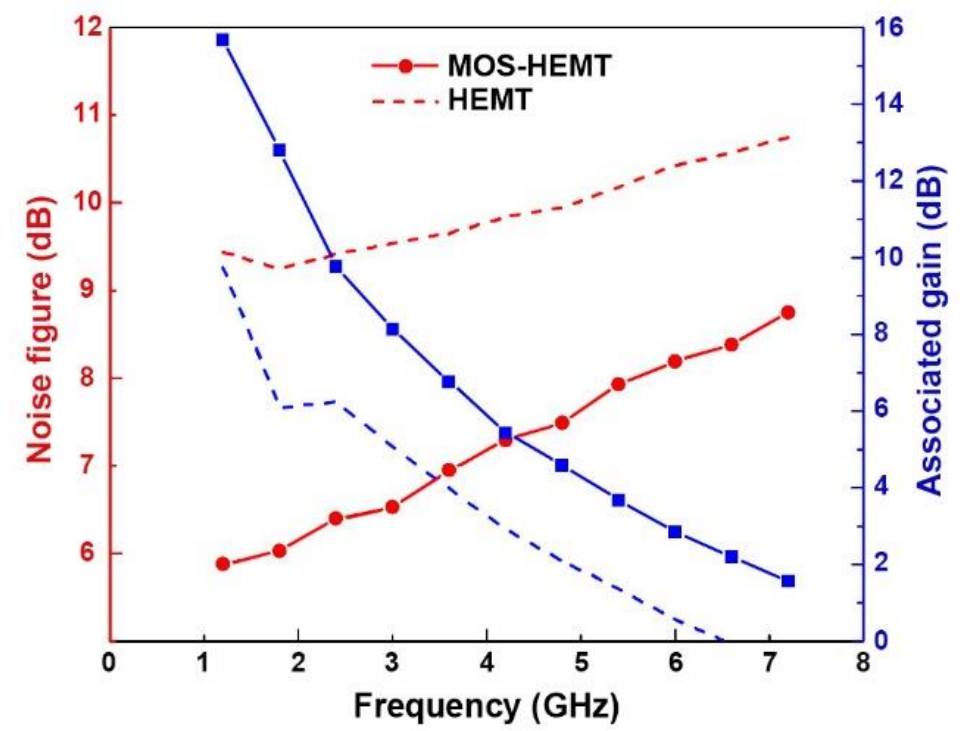

Figure 8. The comparison of noise figure and associated gain for both devices.

The main noise sources of HEMTs include shot noise, hot-electron noise, and generationrecombination noise $[27,28]$. The Schottky barrier corresponding to the gate current is associated with shot noise. As mentioned previously, owing to the decreased leakage current shown in Figures 6 and 7 for the MOS-HEMT, an improved minimum noise figure was expected. In addition, hot-electron noise due to energetic random electron motion, which can enhance the impact ionization mechanism. Therefore, the reduced impact ionization suppresses the hot-electron noise. Traps at the metal/semiconductor interface may contribute to high-frequency noise [29]. The LPO-grown oxide (i.e., oxidized InAlAs) could decrease dangling bonds to suppress the surface recombination centers to further reduce interface traps. In other words, employing LPO to generate a MOS structure could improve the surface states and enhance the barrier height. In addition, Fermi-level movement is enhanced around the gap as trap density decreases near the interface. However, a very low interface trap density is required for conventional MOSFET, which is different from the composite channel positioned away from the oxidized InAlAs with the Schottky layer and spacer layer for MOS-HEMT. Therefore, the issue of the traps underneath the oxide has little impact on the channel. Based on the above three arguments (i.e., Schottky barrier issue, channel issue, and interface trap issue), the noise figure and associated gains of MOS-HEMT could be improved. The device performances of the inverted-type InAlAs/InAs HEMTs with and without oxidized InAlAs as the gate insulator in this work are summarized in Table 1. Table 2 summarizes the device parameters for the high indium ratio MOS-HEMTs in this work and previous work $[20,22]$.

Table 1. Summary of device performances for the inverted-type InAlAs/InAs HEMTs with and without gate oxide in this work.

\begin{tabular}{ccc}
\hline Gate Oxide & With & Without \\
\hline Maximum $\mathrm{I}_{\mathrm{DS}}(\mathrm{mA} / \mathrm{mm})$ at $\mathrm{V}_{\mathrm{DS}}=1.5 \mathrm{~V}$ & 509 & 441 \\
\hline Peak $\mathrm{g}_{\mathrm{m}}(\mathrm{mS} / \mathrm{mm})$ at $\mathrm{V}_{\mathrm{DS}}=1.5 \mathrm{~V}$ & 327 & 243 \\
\hline Turn-on voltage $(\mathrm{V})$ & 3.98 & 1.54 \\
\hline Reverse gate-to-drain breakdown voltage $(\mathrm{V})$ & -4.6 & -2.5 \\
\hline Minimum noise figure $\mathrm{NF}_{\min }$ at $1.2 \mathrm{GHz}(\mathrm{dB})$ & 5.88 & 9.44 \\
\hline Associated gain at $1.2 \mathrm{GHz}(\mathrm{dB})$ & 15.67 & 9.74 \\
\hline
\end{tabular}


Table 2. Summary of device parameters for proposed oxidized InAlAs on MOS-HEMTs in this work and previous work.

\begin{tabular}{cccc}
\hline Type & Inverted-Type (This Work) & Normal-Type Ref. [20] & Normal-Type Ref. [22] \\
\hline Substrate & $\mathrm{InP}$ & $\mathrm{GaAs}$ & $\mathrm{GaAs}$ \\
\hline Channel & $\begin{array}{c}\mathrm{In}_{0.53} \mathrm{Ga}_{0.47} \mathrm{As} / \\
\mathrm{InAs} / \mathrm{In}_{0.53} \mathrm{Ga}_{0.47} \mathrm{As}\end{array}$ & $\mathrm{In}_{0.53} \mathrm{Ga}_{0.47} \mathrm{As}$ & $\mathrm{In}_{0.53} \mathrm{Ga}_{0.47} \mathrm{As}$ \\
\hline $\begin{array}{c}\text { Hall mobility }\left(\mathrm{cm}^{2} / \mathrm{Vs}\right) / \mathrm{sheet} \\
\text { carrier concentration }\left(\mathrm{cm}^{-2}\right) @\end{array}$ & $14,262 / 2.07 \times 10^{12}$ & $7000 / 2 \times 10^{12}$ & $7000 / 2 \times 10^{12}$ \\
$300 \mathrm{~K}$ & 1 & 0.65 & 0.65 \\
\hline Gate length $(\mu \mathrm{m})$ & 509 & 252 & 424 \\
\hline $\begin{array}{c}0.65 \\
\text { Maximum } \mathrm{I}_{\mathrm{DS}}(\mathrm{mA} / \mathrm{mm})\end{array}$ & 327 & 226 & 254 \\
\hline Peak $\mathrm{g}_{\mathrm{m}}(\mathrm{mS} / \mathrm{mm})$ & & \\
\hline
\end{tabular}

\section{Conclusions}

In this study, we used the LPO to grow oxidized InAlAs film on a Schottky layer for fabricating inverted-type InAlAs/InAs MOS-HEMT. A thin InAs layer was inserted within the InGaAs sub-channel layer to enhance the device performance. The proposed inverted-type InAlAs/InAs MOS-HEMT exhibited higher drain current density and $\mathrm{g}_{\mathrm{m}}$ compared with those of the reference HEMT. Besides, a suppressed noise figure and enhanced associated gain can be achieved based on the improved gate current density, decreased impact ionization, and reduced interface traps due to the oxidized InAlAs film. These results indicate that the proposed inverted-type InAlAs/InAs MOS-HEMT can provide an alternative option for device applications.

Author Contributions: Conceptualization, K.-W.L.; methodology, H.-C.L.; validation, Y.-M.C. and K.W.L.; formal analysis, Y.-M.C.; investigation, Y.-M.C. and H.-C.L.; resources, Y.-H.W.; data curation, Y.M.C.; writing—original draft preparation, Y.-M.C.; writing—review and editing, K.-W.L.; supervision, Y.-H.W.; project administration, K.-W.L. and Y.-H.W.; funding acquisition, K.-W.L. and Y.-H.W. All authors have read and agreed to the published version of the manuscript.

Funding: This research was funded by the National Science Council (NSC) of Taiwan under contracts NSC 100-2221-E-214-013 and NSC 101-2221-E-006-141-MY3. It was supported in part by the Ministry of Science and Technology (MOST) of Taiwan under contract MOST 109-2221-E-006-075-MY2.

Institutional Review Board Statement: Not applicable.

Informed Consent Statement: Not applicable.

Acknowledgments: The authors would like to thank Long-Ting Chung of I-Shou University for the organization of data and Chia-Hong Hsieh of National Cheng-Kung University for the contribution in XPS spectra.

Conflicts of Interest: The authors declare no conflict of interest.

\section{References}

1. Del Alamo, J.A. Nanometre-scale electronics with III-V compound semiconductors. Nature 2011, 479, 317-323. [CrossRef] [PubMed]

2. Smith, P.M.; Liu, S.M.J.; Kao, M.Y.; Ho, P.; Wang, S.C.; Duh, K.H.G.; Fu, S.T.; Chao, P.C. W-band high efficiency InP-based power HEMT with $600 \mathrm{GHz} \mathrm{f}_{\mathrm{max}}$. IEEE Microw. Guided Wave Lett. 1995, 5, 230-232. [CrossRef]

3. Jo, H.B.; Baek, J.M.; Yun, D.Y.; Son, S.W.; Lee, J.H.; Kim, T.W.; Kim, D.H.; Tsutsumi, T.; Sugiyama, H.; Matsuzaki, H. Lg = 87 nm InAlAs/InGaAs high-electron-mobility transistors with a $\mathrm{g}_{\mathrm{m} \_\max }$ of $3 \mathrm{~S} / \mathrm{mm}$ and $\mathrm{f}_{\mathrm{T}}$ of $559 \mathrm{GHz}$. IEEE Electron Device Lett. 2018, 39, 1640-1643. [CrossRef]

4. Ng, G.I.; Pavlidis, D.; Quillec, M.; Chan, Y.J.; Jaffe, M.D.; Singh, J. Study of the consequence of excess indium in the active channel of InGaAs/InAlAs high electron mobility transistors on device properties. Appl. Phys. Lett. 1988, 52, 728-730. [CrossRef] 
5. Matsumura, K.; Inoue, D.; NaKano, H.; Sawada, M.; Harada, Y.; Nakakado, T. A new high electron mobility transistor (HEMT) structure with a narrow quantum well formed by inserting a few monolayers in the channel. Jpn. J. Appl. Phys. 2018, 30, L166-L169. [CrossRef]

6. Eugster, C.C.; Broekaert, T.P.E.; Del Alamo, J.A.; Fonstad, C.G. An InAlAs/InAs MODFET. IEEE Electron Device Lett. 1991, 12, 707-709. [CrossRef]

7. Ko, H.; Takei, K.; Kapadia, R.; Chuang, S.; Fang, H.; Leu, P.W.; Ganapathi, K.; Plis, E.; Kim, H.S.; Chen, S.-Y.; et al. Ultrathin compound semiconductor on insulator layers for high-performance nanoscale transistors. Nature 2010, 468, 286-289. [CrossRef] [PubMed]

8. Kim, K.-H.; Um, D.-S.; Lee, H.; Lim, S.; Chang, J.; Koo, H.C.; Oh, M.-W.; Ko, H.; Kim, H.-J. Gate-controlled spin-orbit interaction in InAs high-electron mobility transistor layers epitaxially transferred onto Si substrates. ACS Nano 2013, 7, 9106-9114. [CrossRef] [PubMed]

9. Yamada, H.T.; Shigemasa, R.; Fujishiro, H.I.; Nishi, S.; Saito, T. Fabrication of $0.2 \mu \mathrm{m}$ gate pseudomorphic inverted HEMT by phase-shifting technology. Solid-State Electron. 1995, 38, 1631-1634. [CrossRef]

10. Akazaki, T.; Takayanagi, H.; Enoki, T. Kink effect in an InAs inserted-channel InAlAs/InGaAs inverted HEMT at low temperature. IEEE Electron Device Lett. 1996, 17, 378-380. [CrossRef]

11. Li, Q.; Zhou, X.; Tang, C.W.; Lau, K.M. High-performance inverted $\operatorname{In}_{0.53} \mathrm{Ga}_{0.47}$ As MOSHEMTs on a GaAs substrate with regrown source/drain by MOCVD. IEEE Electron Device Lett. 2012, 33, 1246-1248. [CrossRef]

12. Minden, H.T. Thermal oxidation of GaAs. J. Electrochem. Soc. 1962, 109, 733. [CrossRef]

13. Coleman, D.J.; Shaw, D.W.; Dobrott, R.D. On the mechanism of GaAs anodization. J. Electrochem. Soc. 1977, 124, $239-241$. [CrossRef]

14. Bertrand, P.A. The photochemical oxidation of GaAs. Photochem. Oxid. Gaas. 1985, 132, 973-976. [CrossRef]

15. Ren, F.; Kuo, J.M.; Hong, M.; Hobson, W.S.; Lothian, J.R.; Lin, J.; Tsai, H.S.; Mannaerts, J.P.; Kwo, J.; Chu, S.N.G.; et al. $\mathrm{Ga}_{2} \mathrm{O}_{3}\left(\mathrm{Gd}_{2} \mathrm{O}_{3}\right) /$ InGaAs enhancement-mode n-channel MOSFETs. IEEE Electron Device Lett. 1998, 19, 309-311. [CrossRef]

16. Ye, P.; Wilk, G.; Kwo, J.; Yang, B.; Gossmann, H.-J.; Frei, M.; Chu, S.; Mannaerts, J.; Sergent, M.; Hong, M.; et al. GaAs MOSFET with oxide gate dielectric grown by atomic layer deposition. IEEE Electron Device Lett. 2003, 24, 209-211. [CrossRef]

17. Paul, N.C.; Nakamura, K.; Seto, H.; Iiyama, K.; Takamiya, S. Oxidation of InAlAs and its application to gate in-sulator of InAlAs/InGaAs metal oxide semiconductor high electron mobility transistor. Jpn. J. Appl. Phys. 2005, 44, 1174-1180. [CrossRef]

18. Bae, S.J.; Kim, J.M.; Park, C.Y.; Lee, Y.T. Characteristics of InAlAs/InP and InAlP/GaAs native oxides. Solid-State Electron. 2006, 50, 1625-1628. [CrossRef]

19. Wang, H.-H.; Huang, C.-J.; Wang, Y.-H.; Houng, M.-P. Liquid phase chemical-enhanced oxidation for GaAs operated near room temperature. Jpn. J. Appl. Phys. 1998, 37, L67-L70. [CrossRef]

20. Lee, K.-W.; Lee, K.-L.; Lin, X.-Z.; Tu, C.-H.; Wang, Y.-H. Improvement of impact ionization effect and subthreshold current in InAlAs/InGaAs metal-oxide-semiconductor metamorphic HEMT with a liquid-phase oxidized InAlAs as gate insulator. IEEE Trans. Electron Devices 2007, 54, 418-424. [CrossRef]

21. Lee, K.-W.; Lin, K.-L.; Lin, H.-C.; Tu, C.-H.; Hu, C.-C.; Wang, Y.-H. Near-room-temperature selective oxidation on InAlAs and application to $\mathrm{In}_{0.52} \mathrm{Al}_{0.48} \mathrm{As} / \mathrm{In}_{0.53} \mathrm{Ga}_{0.47} \mathrm{As}$ metamorphic HEMTs. J. Electrochem. Soc. 2007, 154, H957-H961. [CrossRef]

22. Lee, K.-W.; Lin, H.-C.; Lee, K.-L.; Hsieh, C.-H.; Wang, Y.-H. Comprehensive study of InAlAs/InGaAs metamorphic high electron mobility transistor with oxidized InAlAs gate. J. Electrochem. Soc. 2009, 156, H925-H929. [CrossRef]

23. Hill, R.J.W.; Droopad, R.; Moran, D.A.J.; Li, X.; Zhou, H.; Macintyre, D.; Thoms, S.; Ignatova, O.; Asenov, A.; Ra-jagopalan, K.; et al. $1 \mu \mathrm{m}$ gate length, $\mathrm{In}_{0.75} \mathrm{Ga}_{0.25}$ As channel, thin body n-MOSFET on InP substrate with transconductance of $737 \mu \mathrm{S} / \mu \mathrm{m}$. Electron. Lett. 2008, 44, 498-500. [CrossRef]

24. Duh, K.; Chao, P.-C.; Smith, P.; Lester, L.; Lee, B.; Ballingall, J.; Kao, M.-Y. High-performance Ka-band and V-band HEMT low-noise amplifiers. IEEE Trans. Microw. Theory Tech. 1988, 36, 1598-1603. [CrossRef]

25. Hamaizia, Z.; Sengouga, N.; Missous, M.; Yagoub, M. A 0.4dB noise figure wideband low-noise amplifier using a novel InGaAs/InAlAs/InP device. Mater. Sci. Semicond. Process. 2011, 14, 89-93. [CrossRef]

26. Fukui, H. Optimal noise figure of microwave GaAs MESFET's. IEEE Trans. Electron Devices 1979, 26, 1032-1037. [CrossRef]

27. Hartnagel, H.L.; Katilius, R.; Matulionis, A. Microwave Noise in Semiconductor Devices; John Wiley \& Sons, Inc.: Hoboken, NJ, USA, 2001.

28. Huang, H.-K.; Wang, C.-S.; Chang, C.-P.; Wang, Y.-H.; Wu, C.-L.; Chang, C.-S. Noise characteristics of InGaP-gated PHEMTs under high current and thermal accelerated stresses. IEEE Trans. Electron Devices 2005, 52, 1706-1712. [CrossRef]

29. Marsh, P.; Pavlidis, D.; Hong, K. InGaAs-Schottky contacts made by in situ plated and evaporated Pt—an analysis based on DC and noise characteristics. IEEE Trans. Electron Devices 1998, 45, 349-360. [CrossRef] 